\title{
Nano-analysis of the Metallic Multilayers Using High Resolution Electron Microscopy
}

\author{
A.Genç*, R. Banerjee**, J. Ringnalda***, D.M. Maher*, H.L. Fraser* \\ * Department of Materials Science and Engineering, The Ohio State University, 2041 \\ College Road, Columbus, Ohio, 43210 \\ ** Department of Materials Science and Engineering, The University of North Texas, \\ UNT Research Park, Denton, Texas, 76207 \\ *** FEI Electron Optics, PO Box 80066, 5600 KA Eindhoven, The Netherlands
}

Thin film multilayers exhibit structural transitions when the layer thickness is reduced to the nanometer scale. These structural transitions often result in crystal structures that would be metastable for the same materials in the bulk form [1]. As the thin film materials used in electronic and optical applications continue to decrease in thickness to the nano-scales, marked changes in functional properties are expected to occur due to changes in the crystal structure of these materials. Therefore, such multilayer systems have been of considerable interest due to the ability to control properties by engineering the structure of materials at these scales. New instrumentation allows for the direct imaging and analysis of such materials in order to link the performance variations with crystal structure variations.

Consequently, results from many metal/metal systems have been reported in the literature, including $\mathrm{Ti} / \mathrm{Al}, \mathrm{Nb} / \mathrm{Zr}, \mathrm{Nb} / \mathrm{Ti}$ and $\mathrm{Co} / \mathrm{Cr}$ [2]. Experimental observations on multilayer systems have illustrated cases where either one or multiple layers can exist with metastable structures, for example; fcc $\mathrm{Ti}$ in $\mathrm{Ti} / \mathrm{Al}$ multilayers, bcc $\mathrm{Zr}$ and hep $\mathrm{Nb}$ in $\mathrm{Nb} / \mathrm{Zr}$ mutlilayers and bcc $\mathrm{Co}$ and hcp $\mathrm{Cr}$ in $\mathrm{Co} / \mathrm{Cr}$ multilayers $[2,3]$.

The techniques that are used for the characterization of these multilayers involve highresolution transmission electron microscopy (HRTEM) and high angle annular dark-field scanning transmission electron microscopy (HAADF-STEM). Traditionally, HRTEM has been applied for morphology, defect and crystal structure analysis of these materials [4]. HRTEM has the great advantage that it yields local information about atomic arrangements, projected along the direction of electron beam at a resolution comparable to the inter-atomic distance. Figure $1 \mathrm{a}$. is a HRTEM image of a cross-section of a $1.5 \mathrm{~nm}$ thick bcc Ti and $2.5 \mathrm{~nm}$ thick bcc Nb multilayer. The HRTEM image clearly reveals that bcc Ti (110) planes are grown epitaxially on the bcc Nb (110) layers. In this study, both HRTEM and HAADF - STEM experiments were performed by using a FEI TITAN ${ }^{\mathrm{TM}}$ transmission electron microscope, operated at $300 \mathrm{kV}$ and equipped with a GATAN UltraScan $^{\mathrm{TM}}$ camera and an annular dark-field detector.

HAADF-STEM is a proven technique where the images are directly interpretable due to the incoherent nature of the imaging process [5]. At high enough scattering angles the intensity variations in the image is atomic number dependent (Z-Contrast). Therefore, in systems like $\mathrm{Cu} / \mathrm{Nb}$ multilayers, where the atomic number difference is significant $\left(\mathrm{Z}^{2}\right.$ ratio $\sim 2$ ), STEM is a very suitable technique to characterize the interface and the 
individual layer structure. Figure $1 \mathrm{~b}$. is a high angle annular dark-field STEM image of a bcc $\mathrm{Cu} /$ bcc $\mathrm{Nb}$ structure where the $\mathrm{Cu}$ and $\mathrm{Nb}$ crystal structure can be identified and the layer thicknesses can be measured as $0.8 \mathrm{~nm} \mathrm{Cu}$ and $3 \mathrm{~nm} \mathrm{Nb}$, respectively.

\section{References}

[1] S.A. Dregia et al., Scripta Materialia, Vol.39, No.2, pp.217-223, (1998)

[2] R.Banerjee et al., Encyclopedia of Nanoscience and Nanotechnology, Marcel Dekker Inc. NewYork (2003)

[3] G.B. Thompson et al., Journal of Materials Research, Vol.19, No.5, pp. 1582-1590, (2004)

[4] R.Banerjee et al., Physical Review Letters, Vol.76, No.20, pp. 3778- 3781, (1996)

[5] S.J. Pennycook et al., Physical Review Letters, Vol.64, No.8, pp.938- 941, (1990)

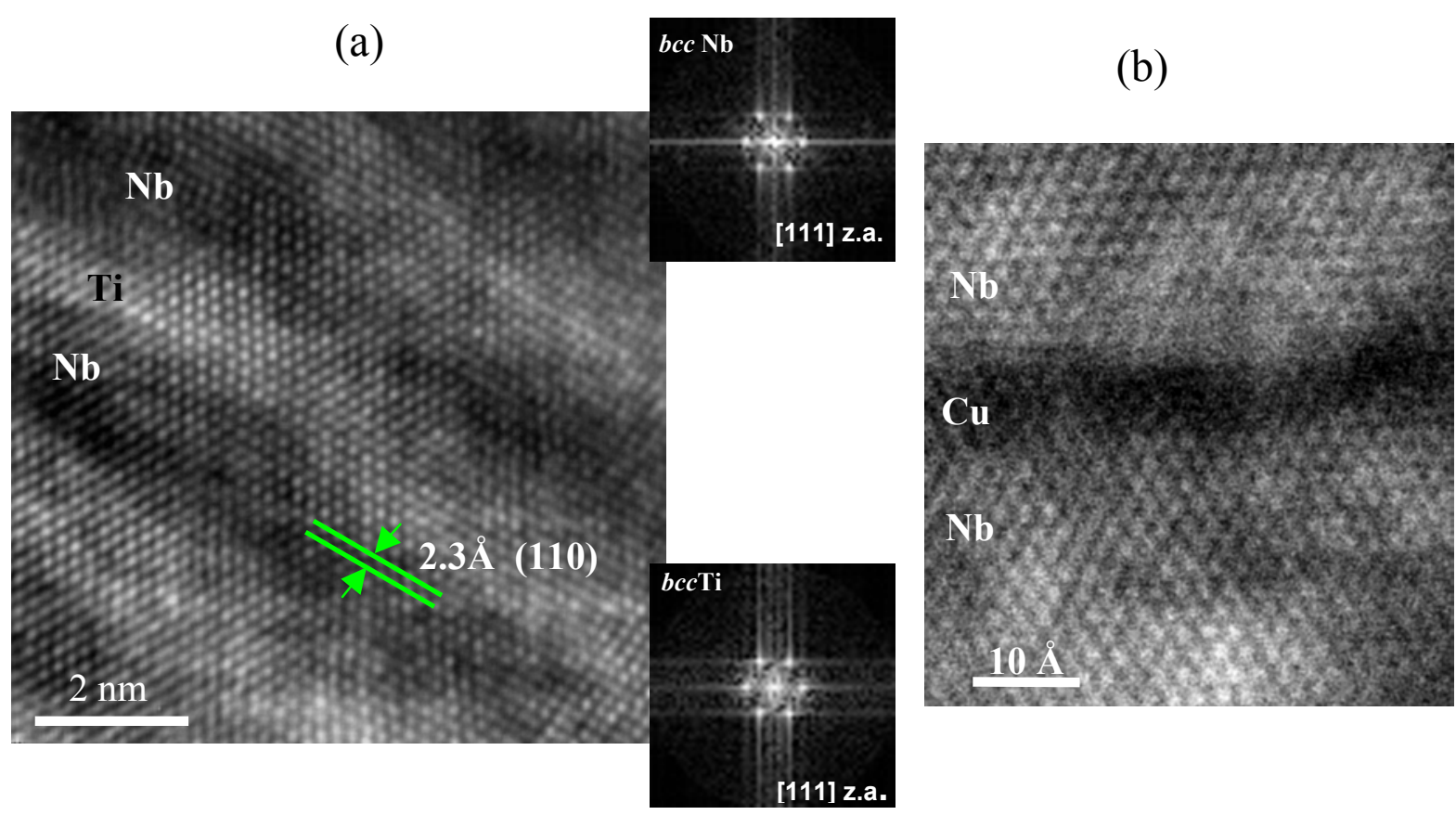

Fig. 1 a. High resolution transmission electron microscopy image of a cross-section of bcc $\mathrm{Ti} /$ bcc Nb multilayer b. Annular dark-field scanning transmission electron microscopy image of a cross-section of bcc $\mathrm{Cu} /$ bcc $\mathrm{Nb}$ multilayer 